\title{
INDIVÍDUO E SOCIEDADE: relações de continuidades e descontinuidades da antropologia filosófica nas ciências sociais
}

\author{
INDIVIDUAL AND SOCIETY: relations of continuities and discontinuities of \\ philosophical anthropology in social sciences
}

Marco Vinicius de Castro*

\begin{abstract}
Resumo
Este artigo tem como objetivo fazer um ensaio analítico das noções de indivíduo e sociedade da sociologia clássica, enfatizando Karl Marx, Émile Durkheim e Max Weber, e refletir como tais noções podem ter sido construídas em relações de continuidades e descontinuidades com a antropologia filosófica nas ciências sociais, principalmente de Thomas Hobbes e Jean-Jacques Rousseau. Para isso, foi feita uma revisão bibliográfica não com o intuito de comparar, mas de aproximar e distanciar tais autores por meio do apontamento genérico de suas principais ideias e reflexões. Ao final dessa breve discussão bibliográfica, espera-se que seja possível identificar as continuidades e descontinuidades nos pensamentos expostos desses autores, assim como mostrar que as noções de indivíduo e sociedade da sociologia clássica podem ter sido influenciadas pelas continuidades e descontinuidades inerentes ao debate da antropologia filosófica nas ciências sociais.
\end{abstract}

Palavras-chave: Indivíduo; Sociedade; Continuidades e Descontinuidades.

\begin{abstract}
This article has got the purpose of making an analytical essay on the notions of individual and society of classical sociology, emphasizing Karl Marx, Émile Durkheim and Max Weber, and reflect how such notions may have been constructed in relations of continuities and discontinuities with philosophical anthropology in social sciences, mainly of Thomas Hobbes and Jean-Jacques Rousseau. For this, a bibliographic review was made not to compare, but to approximate and hold off such authors through the generic pointing of their main ideas and reflections. At the end of this brief bibliographical discussion, it is hoped that it will be possible to identify the continuities and discontinuities in the exposed thoughts of these authors, as well as describe how the notions of individual and society of classical sociology may have been influenced by the continuities and discontinuities inherent of the debate of philosophical anthropology in social sciences.
\end{abstract}

Keywords: Individual; Society; Continuities and Discontinuities.

\footnotetext{
* Doutorando em Ciências Sociais pelo Programa de Pós-Graduação em Ciências Sociais (PPGCSO) da Universidade Federal de Juiz de Fora (UFJF), Minas Gerais/Brasil. Financiado pela CAPES. E-mail: marco.castro@ufv.br
} 


\section{Introdução}

Este trabalho tem por objetivo fazer um ensaio analítico sobre as noções de indivíduo e sociedade pelo prisma das continuidades e descontinuidades da antropologia filosófica nas ciências sociais. O ponto de partida foi uma questão basilar: Em que medida as continuidades e descontinuidades inerentes ao debate jusnaturalista podem ter influenciado a construção das noções de indivíduo e sociedade nas ciências sociais? Dessa questão, surgiram outras, a seguir: Quais as principais continuidades e descontinuidades da antropologia filosófica clássica das ciências sociais? É possível que esse debate tenha proposto de forma implícita as relações entre indivíduo e sociedade enquanto filosofava sobre a relação entre natureza humana e ordenamento sociopolítico? A partir de qual momento se pode começar a pensar o fim da tradição da antropologia filosófica e o começo da sociedade como fator analítico? E, por fim, esse debate pode ter servido de inspiração para as noções de indivíduo e sociedade como objeto da sociologia clássica?

Essas, contudo, não são questões simples de serem respondidas. Então, neste ensaio, não se pretende respondê-las definitivamente, mas apontar possibilidades de respostas e caminhos para o debate. Para isso, foi feita uma revisão bibliográfica, não com o intuito de comparar sistematicamente, mas de apontar de forma genérica as principais ideias de alguns autores considerados clássicos nas ciências sociais (Karl Marx, Émile Durkheim e Max Weber) e, seja explícita ou implicitamente, tentar mapear como suas principais categorias analíticas e abstrações estão em relações de continuidades e descontinuidades com os pensamentos de Thomas Hobbes, Jean-Jacques Rousseau, David Hume e Alexis Tocqueville.

Para cumprir esse objetivo, o artigo está dividido em duas partes. A primeira apresenta uma breve discussão sobre as relações entre natureza humana e Estado político, por meio das noções de liberdade e igualdade, conflito e ordem sociopolítica, egoísmo e empatia, naturalidade e artificialidade, dentre outras, procurando mostrar como a partir delas derivam as relações entre indivíduo e sociedade em sua fase germinal. Aqui enfatizando as principais ideias de Thomas Hobbes e Jean-Jacques Rousseau. Ainda nesta parte, haverá uma seção intermediária em que a natureza humana não será mais o ponto de partida analítico, mas uma imaginação social. Isso será feito a partir de dois autores - 
David Hume e Alexis Tocqueville —, que apesar de ainda apresentarem continuidades com o pensamento dos autores das duas primeiras seções, não compartilhavam com algumas de suas ideias.

A segunda parte será voltada para o debate da relação entre indivíduo e sociedade, sobretudo tentando apontar, de forma mais implícita do que explícita, como as reflexões desses autores estavam em diálogos, não só entre si, mas também com as reflexões dos autores da primeira parte. A primeira seção dessa parte irá expor algumas ideias de Karl Marx, sobretudo como esse autor concebe a relação entre indivíduo e sociedade por meio das relações materiais de produção e reprodução da vida humana; e ainda em diálogo com a primeira parte, como ele concebe um possível ordenamento sociopolítico. A segunda seção será voltada para alguns pensamentos de Emile Durkheim, tentando aproximar suas inspirações e críticas aos autores da primeira parte. E, por último, a ênfase será em Max Weber, sobretudo como esse autor recupera a noção de ação racional. Espera-se que ao final dessa breve revisão bibliográfica, seja possível identificar as continuidades e descontinuidades nos pensamentos expostos desses autores, e assim perceber como as noções de indivíduo e sociedade podem ter sido influenciadas pelas continuidades e descontinuidades do debate inerente à antropologia filosófica nas ciências sociais.

\section{Os homens, a sociedade, o estado natural e o estado político}

Esta seção se dedica a descrever e analisar algumas ideias de Thomas Hobbes e Jean-Jacques Rousseau. Possui três subseções, a primeira dedicada a Thomas Hobbes, a segunda a Rousseau, e a terceira, com o propósito de ampliar o debate, acrescenta ao diálogo as ideias de David Hume e Alexis de Tocqueville.

\subsection{O estado de natureza e o estado político no Leviatã de Thomas Hobbes}

Antes de fazer uma jornada pelo pensamento de Thomas Hobbes (1588-1679), é interessante contextualizar sua obra. A Revolução na Inglaterra é caracterizada por um conjunto de fenômenos que ocorreram entre os anos de 1629 e 1688, e esses fenômenos são fundamentais para a compreensão das razões circunstanciais que levaram Hobbes (1974) a escrever sua obra no século XVII. Essa revolução foi demasiadamente violenta e, para Hobbes, causava uma sensação de insegurança generalizada, de modo que a guerra 
civil fosse análoga ao seu conceitual estado de natureza, no qual os comportamentos dos homens eram regidos pela desconfiança, a genitora de toda violência daquele contexto.

Hobbes foi um dos primeiros pensadores da modernidade a fazer uma abordagem filosófica para refletir e explicar a natureza humana. Para isso, ele parte de uma questão base: “O que nós somos?" Para respondê-la, ele se mune do aforismo grego "conhece a ti mesmo", que em sua obra foi traduzido como "leia a si mesmo". Além disso, Hobbes também parte da premissa empirista de observar os fatos e daí fazer suas abstrações racionais dedutivas, e conclui que todos os homens são naturalmente iguais, uma vez que as diferentes desigualdades oriundas das diferenças naturais não são suficientes para promover uma desigualdade generalizada entre os homens. Para ele, a base dos comportamentos dos homens são as sensações físicas e psicológicas, e eles agem para ter sensações boas e evitar as más, de modo que a motivação básica do comportamento humano sejam as sensações.

Mas no suposto estado de natureza quem define o que é bom e o que é ruim, ou melhor, o que são as coisas boas e as coisas más? De acordo com o pensamento de Hobbes (1974), a liberdade natural existe no estado de natureza, e é por meio desse tipo de liberdade que cada indivíduo define o que é bom e o que é ruim. Além da igualdade e da liberdade natural, Hobbes especula uma série de características do homem natural, definindo-as em movimentos vitais, voluntários e as sensações, e destes últimos derivam suas paixões e desejos. Uma das sensações enfatizadas em $O$ Leviatã é o medo, pois Hobbes considera que os seres humanos temem, basicamente, duas coisas, o sofrimento e a morte.

Outro apontamento da antropologia filosófica de Hobbes é que os homens são naturalmente egoístas, salientando que esse egoísmo não tem nada a ver com a agressividade pura, mas com a desconfiança dos homens de uns para com os outros. Partindo dessas supostas características inerentes à natureza humana, sobretudo da existência de uma infinidade de paixões egoístas exacerbadas, ele supõe e define o estado natural, que, genericamente, seria todos poderem agir de acordo com suas liberdades naturais e, sendo iguais nesse aspecto, possibilitaria uma guerra de todos contra todos. Esse estado faz aflorar o temor e a desconfiança, e essa situação pode ser análoga a toda 
vez que existe uma crise no poder institucionalizado e este não consegue oferecer segurança física e confiança moral às pessoas.

Para contornar essa suposta situação de insegurança e desconfiança de todos para com todos, Hobbes propõe uma autoridade para controlar a natureza humana, e essa autoridade não é nada mais e nada menos do que o Estado. Uma das características da natureza humana propostas por Hobbes é a racionalidade, sendo ela uma capacidade de calcular utilitariamente, por meio das experiências, quais meios seriam eficientes para alcançar certos fins. A partir dessa noção de racionalidade, ele propõe a criação do Estado, ou do Leviatã, como um meio eficiente para reconhecer a conflituosa natureza humana e acabar com a guerra proveniente dela. O Estado ou Leviatã, nessa perspectiva, seria um artifício humano não natural e fruto da razão que seria capaz de criar moralidade, ou melhor, códigos para impor à natureza humana deveres a serem seguidos.

Mas como instituir o Estado? Qual seria a forma correta, eficiente e legítima? Para Hobbes (1974), a forma correta, eficiente e legítima de instituir o Estado seria por meio do contrato racional, este que não é visto como um consenso em que os indivíduos se reúnem e aceitam a criação do Estado para prover segurança e confiança, mas um acordo em que os indivíduos abrem mão de suas liberdades naturais em troca de segurança e confiança. Nesse pacto social, os indivíduos escolhem um governo que Hobbes não define claramente em seu livro (HOBBES, 1974), que pode ser visto como uma organização no sentido de pessoa jurídica, pois este promove a segurança e confiança, além de estabelecer as margens de liberdades, escolhas e benefícios. Na relação entre governo e governados, os homens aceitam obedecer ao Leviatã de forma absoluta, uma vez que este deve prover segurança e confiança, e caso ele não seja capaz de prover isso, o contrato não tem razão de continuar vigente, pois os homens retornam ao estado natural. Vale observar que o Estado proposto por Hobbes compromete a propriedade privada, pois somente ao Leviatã cabe a propriedade final sobre tudo, inclusive sobre a liberdade natural dos homens.

Essas noções de estado de natureza e Estado político de Hobbes podem ser vistas como o germe da ideia da existência de uma autoridade, por meio da sociedade, para estabelecer vida coletiva entre os homens, assim como das relações entre indivíduo e sociedade. Para Hobbes, não existe ordem social no estado de natureza, ou melhor, não existe ordem social natural e o estado de natureza é caracterizado por uma profunda 
anomia, de modo que não existe nada justo ou injusto devido à tendência conflituosa dos homens e da falta de moralidade; dessa falta de moralidade emerge um mundo sedimentado na desconfiança e, consequentemente, na violência. Nessa perspectiva, o estado de natureza é caracterizado pelo caos de subjetividade, uma vez que cada indivíduo, por meio de sua liberdade natural, age baseado em sua própria imaginação sobre o que seria certo ou errado.

O Estado é o grande definidor, segundo Hobbes (1974), e o contrato estabelecido por meio dele é que vai controlar as doutrinas e as ideias dos homens, ou melhor, as suas paixões e desejos, julgando-as a partir de uma ordem estabelecida por ele, e freando o caos de subjetividade. Com o contrato feito com o Leviatã, que pode ser visto como a constituição de um Estado, é que se passa a ter critérios para controlar o caos de subjetividade e, desta maneira, passa-se a evitar a sedição e os conflitos dentro da sociedade e, consequentemente, do Estado.

\subsection{O estado de natureza e o estado político em Rousseau}

Em continuidades e descontinuidades com Hobbes, a vida de Rousseau (17291778) precede o que ficou conhecida como a Revolução Francesa (1789-1799), período também composto por um ciclo de fenômenos caracterizados por turbulências sociais e políticas e, portanto, existe um debate aceitável de literaturas que consideram seus pensamentos como fogo catalisador desses movimentos. Embora haja controvérsias sobre isso, ele é considerado um dos principais pensadores do Iluminismo, pois pactuava com alguns preceitos da filosofia iluminista, embora rechaçasse outros. Existe também um debate aceitável que o considera como um dos precursores do Romantismo. Feito essa breve e sucinta contextualização, então vamos às suas principais ideias.

Em sua segunda participação nos concursos da Academia de Dijon, em 1754, Rousseau (2010) proferiu seu Discurso sobre a origem e os fundamentos da desigualdade entre os homens, no qual ele respondeu à pergunta: qual a origem da desigualdade entre os homens, e é ela autorizada pela lei natural? Existia outra questão aí implícita que pode ser traduzida da seguinte maneira: a desigualdade entre os homens é legítima pela lei natural? Como respondeu negativamente a essa questão, ele ficou em segundo lugar no 
concurso, mas seu discurso ficou eternizado e ninguém se lembra de quem ficou em primeiro lugar.

Na resposta de Rousseau, ele expõe suas principais ideias sobre o que seria a natureza humana. Para Rousseau, se existiu um estado de natureza - parte da suposição de que existiu -, ele recupera alguns caracteres da natureza humana pensados por Hobbes, mas que não foram enfatizados em sua obra, sendo eles a piedade, o instinto de conservação, a inocência e a predisposição à perfectibilidade. Basicamente ele concebia o instinto de conservação, assim como Hobbes, como uma volição de não sofrer violência e de não morrer, a inocência perpassaria por um sentimento solidário de piedade e empatia, e a perfectibilidade, capacidade de se adequar e se aperfeiçoar às condições da vida. A perfectibilidade era proveniente do uso da razão, que ele divide entre aquela que leva os homens a trabalhar na agricultura, tornando-os fortes, saudáveis e bons soldados, e a que perpassa pelas ciências e artes, podendo ser classificadas em razão prática e razão sistemática, embora Rousseau (2014) não as conceitue desta maneira. É interessante notar que para ele, a relação entre os homens na sociedade, de forma implícita, também precede o estado político, só que o estado natural não é caracterizado pelo caos de subjetividade, pois nele os homens são mais piedosos e menos egoístas do que no Estado político. A propriedade privada também é fruto da razão sistemática e alvo de suas críticas (ROUSSEAU, 2010).

Se existiu o estado de natureza, para Rousseau, ele foi corrompido. Mas o que causou a corrupção do homem? Foi o uso da razão, sobretudo da razão que perpassa pelas ciências e artes, ou seja, da razão sistemática, pois seria por meio do uso da razão que os homens se corromperam e, consequentemente, findou a piedade entre os homens e despertou o egoísmo entre eles. Dessa maneira, o uso sistemático da razão desperta o egoísmo, e deste egoísmo é que se estabelece a propriedade privada, e quando se cria a propriedade privada é que se criam também as diferenças entre ricos e pobres, fortes e fracos, ou melhor, as desigualdades. É exatamente por ser crítico do uso sistemático da razão que se estabelecem controvérsias ao caracterizar Rousseau (2010) como um iluminista, mas que ao mesmo tempo defende um pacto social e um Estado não absolutista, porém este não é o cerne dessa exposição. 
E o Estado político, de onde ele surge? Para Rousseau, ele é um mecanismo de alienação dos direitos naturais e manutenção das desigualdades, que surgiu quando os poderosos sentiram a necessidade de criar um instrumento de legitimação das desigualdades entre os homens. Esse Estado político é instaurado pela proposição de um contrato, que Rousseau (2010) considera ilegítimo, pois é feito entre indivíduos desiguais; os pobres aceitam-no porque ou são enganados, ou não têm nada a perder. Criado esse Estado ilegítimo, Rousseau argumenta que continua o processo de corrupção e de decadência humana, sobretudo quando se trata da solidariedade que perpassa pelos sentimentos de empatia e piedade.

Então seria possível criar um Estado político legítimo? Para o autor é impossível voltar ao estado de natureza, isso fica evidente na metáfora do prefácio do seu discurso sobre as desigualdades entre os homens, quando discorre sobre a estátua de Glauco deteriorada e que perdeu sua forma original. Mas é possível voltar a uma igualdade próxima à do estado natural, e no livro Do contrato social, publicado em 1762, Rousseau (2012) expõe melhor o que poderia ser um Estado criado por um contrato legítimo.

O Estado político legítimo seria instituído por um contrato feito entre homens livres e iguais, em que todos participariam do acordo e decidiriam ao mesmo tempo, uma vez que são simultaneamente súditos e cidadãos. A soberania, nessa perspectiva, é o que acontece no decurso das decisões da vontade geral. Nesse sentido, todos são cidadãos e participam da assembleia do povo, vista como soberana, que seria uma reunião de todos os homens livres e iguais, que legislam, e todos também são simultaneamente súditos, pois obedecem às decisões dessa assembleia e não a questionam, pois essas decisões representam a vontade geral, e ela, supostamente, quer o bem de todos. A vontade geral exprime a soberania do povo, que Rousseau (2012) considera absoluta, infalível e inalienável. Dessa maneira ele concebe a ideia de democracia direta em contraposição ao absolutismo implicitamente proposto por Hobbes, pois isto não está explícito em sua obra.

O contrato entre indivíduos livres e iguais, na obra de Rousseau, pode ser visto como um artifício entre os homens para estabelecer a harmonia e a cooperação, de modo que esse pacto social crie uma comunidade igualitária por meio do exercício da liberdade e igualdade natural de todos. O novo corpo soberano é o povo, que por intermédio da vontade geral dirige o Estado político e, consequentemente, controla o egoísmo. Esse 
contrato entre homens livres e iguais é o que formaria uma comunidade ética e promoveria boas leis.

\subsection{Princípio do fim da tradição jusnaturalista e a emergência da imaginação social}

David Hume (1711-1776) foi um filósofo escocês, cuja metafísica é marcada pelo empirismo radical e pelo ceticismo, e com ele pode-se começar a pensar o princípio do fim da tradição jusnaturalista. Para Hume (2007), o estado de natureza deve ser considerado como uma mera ficção, não muito diferente da idade do ouro inventada pelos poetas. É interessante salientar também que, para Hume, a razão não leva os homens a um ordenamento social e político justo, como almejava Hobbes, e tampouco o interesse público é capaz de fazer o mesmo, como propunha Rousseau. Por essa via, um ordenamento sociopolítico justo, consoante Hume, depende de uma convenção entre os homens que consiga ordenar suas condutas e promover a diferença entre o interesse público e o privado, pois o egoísmo faz parte da conduta humana e estará sempre presente na sociedade. Assim, Hume propõe de forma tácita o que entende como relação entre homens e sociedade.

Por esse caminho, a concepção metafórica de mundo de Hume, ainda em diálogo com a tradição jusnaturalista, projeta que os homens aprendem, por experiência, que viver em sociedade é vantajoso, ou seja, viver em sociedade é um recurso para os homens, e esse artifício é uma singularidade da espécie. Nessa perspectiva, Hume insere a ideia germinal de que é pela sociedade que os homens são capazes de superar o natural e, concomitantemente, a sociedade é um recurso oriundo de uma exigência natural da espécie humana. Interessante notar que aqui aparecem imbricadas as noções de natureza e sociedade, uma vez que Hume julga que é da natureza humana a necessidade da união em sociedade e, ao mesmo tempo, esta é um recurso da natureza humana, ou seja, considera a socialidade, no sentido de predisposição dos homens de viver em sociedade, como um instinto natural.

O século XIX inaugura os estudos comparados, e Tocqueville (1805-1859) foi um dos pioneiros desse tipo de estudo, assim como um autor que se distancia do jusnaturalismo ao mesmo tempo em que carrega algumas categorias dessa corrente em suas análises. Tocqueville $(2000,2005)$ era um juiz que foi convocado pela França para 
visitar os EUA, ou o "Novo mundo", como este país também era conhecido, com a finalidade de estudar o sistema prisional, porém fez mais do que isso. Fez observações que podem ser vistas como a semente do trabalho de campo nas ciências sociais, e muitas reflexões sobre a democracia, comparando os sistemas existentes nos EUA e na Europa (França e Inglaterra) a partir das "realidades" sociais observadas, e alegou que a democracia era uma revolução em andamento, o que o levou a fazer uma predição de que todos os Estados e sociedades autoritários tenderiam a ir em direção à democracia, que se tornaria um sistema político por excelência no futuro.

Mas o que viria a ser democracia? Para responder à questão — que parece simples, mas não é -, Tocqueville começou suas reflexões baseadas em observações e comparações de fatos, isto é, nos diferentes níveis da realidade social, assim como dos elementos micro e macro inerentes a essas realidades. A democracia, para ele, é caracterizada por dois elementos que já apareceram nas seções anteriores: a liberdade e a igualdade, só que eles têm de ser ponderados, como também já foi visto. Consoante Tocqueville, liberdade e igualdade não são vistas como opostas, mas sim como compatíveis e complementares, pois a igualdade é vista como um meio instrumental com a finalidade de prover o exercício da liberdade. Uma das grandes inspirações dessas análises, aparentemente, vem de Rousseau, uma vez que Tocqueville descreve sua observação empírica sobre a democracia em analogia com a soberania do povo por meio da vontade geral.

Tocqueville também apresenta os costumes e a sociedade americana por meio do fornecimento de informações concretas, analisa os detalhes das instituições sociais e do comportamento político dos cidadãos, assim como da cultura, tudo marcado pela democracia. Nesse sentido, a ideia de democracia do autor perpassa por um governo livre e que não deve desconsiderar os interesses da sociedade que se efetiva por meio da vontade do povo, pois esta vontade não é apenas uma mudança no regime político, sobretudo é uma nova forma de organização social. Ademais, a democracia, para Tocqueville, é um poder invisível e diluído pela sociedade afora, embora não menos despótico, pois também é um tipo de ordenamento social.

Interessante notar que essas observações históricas e sociológicas comparadas de Tocqueville (2000, 2005), assim como as reflexões filosóficas de Hume (2007), se 
distanciam das ideias de estado de natureza ou homem natural, conforme foi visto nas duas seções anteriores, mas ainda carregam continuidades e descontinuidades dessas ideias em suas reflexões, como as relações entre igualdade e liberdade, público e privado, egoísmo e cooperação, dentre outras, e se debruçam sobre como essas relações podem ser ponderadas com o intuito de estabelecer um ordenamento sociopolítico capaz de reprimir as paixões individuais e ordenar suas condutas, para assim estabelecer uma vida coletiva harmoniosa e justa. Resta agora analisar, dentro do espectro dos autores considerados clássicos da sociologia, como estas ideias podem ter servido de inspiração na construção de suas noções de indivíduo e sociedade.

\section{Indivíduo e sociedade na sociologia clássica}

A seção anterior descreveu algumas ideias basilares da filosofia antropológica. Esta seção se dedica à relação sociedade-indivíduo, objeto central das ciências sociais, destacando o pensamento de Karl Marx, Émile Durkheim e Max Weber, procurando identificar continuidades e descontinuidades com o pensamento dos autores vistos na primeira parte.

\subsection{Karl Marx e as relações materiais da produção da vida humana}

Marx (1818-1883), assim como Tocqueville, é um autor do contexto pós Revolução Francesa. Sobre Marx, é feita uma divisão genérica de sua obra em dois blocos, a do jovem Marx, considerada de cunho mais filosófico, e a do velho Marx, em que o autor volta-se para uma ciência da sociedade, mas é interessante frisar que a filosofia de Marx é baseada em observações sociológicas, assim como a filosofia de Tocqueville. A Ideologia alemã (MARX; ENGELS, 2007), para Giddens (1984, p. 49), é a "primeira obra em que Marx expõe as ideias de sua maturidade", pois foi a partir dela que ele desenvolveu seus principais temas, como: (a) a totalidade da história universal é a história do homem pelo trabalho humano; (b) o conceito de alienação, que tem de ser estudado e compreendido como um fenômeno histórico de formações sociais específicas; (c) sua teoria do Estado e sua futura superação pela sociedade; (d) o materialismo histórico como perspectiva analítica da sociedade; (e) e a sua teoria da práxis revolucionária. 
A dialética entre sujeito e objeto, isto é, entre os indivíduos e o mundo material ou natural, é o cerne da filosofia de Marx, pois a consciência humana é condicionada por essa relação e, dessa maneira, os indivíduos dão forma ao mundo em que vivem e concomitantemente também são formados por ele (GIDDENS, 1984). Por essa via de entendimento, a análise das questões inerentes aos processos das relações materiais de produção e reprodução da vida humana assume um papel preponderante no pensamento de Marx.

Claramente inspirado nas obras de Rousseau, sobretudo quando se trata do fim da propriedade privada, da preeminência do público sobre o privado, mas também se diferenciando quando se distancia das especulações sobre a natureza humana e propõe o fim do Estado, Marx insere um elemento central em sua análise, as classes sociais. $\mathrm{O}$ materialismo histórico de Marx e Engels (2007) decorre de eles verem a história de forma dialética e, ou seja, ela se desenvolve a partir da dinâmica da luta de forças antagônicas. Em termos gerais, eles, a partir de críticas à religião, a Hegel, aos neo-hegelianos e ao idealismo, mantêm a ideia hegeliana de que o movimento de luta de contrários inerentes ao processo histórico acontece em três momentos: a tese, antítese e síntese, porém Marx e Engels fazem um revés na dialética de Hegel, contrapondo o seu "indivíduo espiritual" ao "indivíduo sensível e real" de Feuerbach, e partem do argumento de que a vida social é substancialmente prática, enfatizando a atividade sensível do indivíduo, para assim colocarem a contradição e o conflito como substância da atividade humana sensível e prática. Isto é, basicamente, o que ficou conhecido como luta e unidade dos contrários no materialismo histórico e na teoria da práxis revolucionária de Marx e Engels.

Os burgueses são indivíduos proprietários preocupados com seus interesses particulares e com a ampliação de seus negócios (MARX, 2010). Giddens (1984, p. 75) explana que, "segundo Marx, o poder econômico e o poder político se relacionam intimamente, se bem que não de forma inseparável". Mais adiante, ele continua e argumenta que "o sistema legal e judicial moderno é o principal suporte ideológico do Estado burguês" (GIDDENS, 1984, p. 76). Nesse sentido, o Estado e a religião são entendidos como fatores de alienação, e a ideologia, por meio dos ideais de liberdade e igualdade, é vista como uma dissimulação que oculta a realidade da dominação intrínseca à sociedade capitalista, ou seja, da burguesia sobre o proletariado. As relações entre 
Estado, direitos, ideais de liberdade e igualdade, e também a noção de propriedade, para Marx e Engels, surgem para garantir o direito à propriedade privada e assegurar os interesses da classe burguesa, pois o direito privado se desenvolve concomitantemente à propriedade privada para proteger os interesses da burguesia, criando uma ilusão por meio da ideologia jurídica. Interessante observar que o Estado, o direito, os indivíduos e a sociedade são categorias submetidas à historicidade, e não estão na continuidade e descontinuidade de supostos direitos naturais inerentes aos debates da antropologia filosófica nas ciências sociais.

Em suma, burgueses e proletários se configuram, concomitantemente, como classes complementares e antagônicas e, a partir de uma teoria da práxis revolucionária, Marx e Engels estabelecem que uma tomada de consciência racional desse antagonismo poderia levar a classe proletária a se organizar e assumir o Estado, e por meio deste promover uma revolução e acabar com a propriedade privada, a divisão do trabalho, a alienação, a divisão da sociedade em classes, o capitalismo e, por fim, com o próprio Estado. Por essa via, as proposições de Marx e Engels colocaram em xeque as idealizações dos contratualistas que concebiam o Estado como esfera positiva da sociedade.

\subsection{Durkheim e a moral como fonte da ordem social}

Durkheim (1858-1917) foi um autor contextual de meados do século XIX e princípio do século XX. Ao entender a sociedade como algo sui generis e propor que os fatos sociais são reais e passíveis de estudos empíricos em diferentes sociedades, ele (DURKHEIM, 1983a) concebe que eles podem ser observados e descritos, e institucionaliza academicamente, na França, a sociologia como ciência empírica da vida moral, tornando-se um dos pais fundadores da disciplina. Para Giddens, a tese que Durkheim se propõe a defender em A divisão do trabalho "é que a complexa sociedade moderna não tende inevitavelmente para a desintegração, apesar do declínio da significação das crenças morais tradicionais que nela se verifica" (GIDDENS, 1984, p. 117). Nessa perspectiva, Durkheim propõe que, ao mesmo tempo em que se torna mais autônomo, o indivíduo depende cada vez mais da sociedade. 
Ele discerne a divisão do trabalho sob uma lógica diferente do "economicismo", e analisa o efeito moral por ela produzido, sobretudo aquele institucionalizado no direito de uma dada sociedade, e como por meio desse direito desdobra-se a função imanente à divisão do trabalho de causar um sentimento de solidariedade entre os indivíduos, sentimento que pode ser análogo à empatia em Rousseau. Nesse sentido, a divisão do trabalho é entendida como um dos elementos propulsores da coesão do corpo social e formador da consciência coletiva, criando laços morais de individualidade, interdependência e cooperação entre os indivíduos de uma dada sociedade.

A religião também foi um dos principais objetos de estudos da sociologia de Durkheim. De acordo com Giddens (1984, p. 156), "Durkheim sublinha em suas primeiras obras a importância da religião na sociedade, na sua qualidade de fonte original de todas as ideias morais, filosóficas, científicas e jurídicas surgidas posteriormente”. No esforço de tentar entender a natureza religiosa que permeia a vida dos indivíduos, em As formas elementares da vida religiosa, Durkheim propõe (2000, p. 147) estudar "a religião mais primitiva e mais simples atualmente conhecida, analisá-la e tentar explicá-la". Para ele, "sabe-se há muito tempo que os primeiros sistemas de representações que o homem fez para si do mundo e de si mesmo são de origem religiosa" (2000, p. 154), isto é, ele entende que as cosmologias religiosas foram os primeiros sistemas coletivos de representação do mundo. A conclusão geral a que chega é de que "a religião é uma coisa eminentemente social" (DURKHEIM, 2000, p. 155).

Genericamente, diferentemente da filosofia utilitarista e de Marx, Durkheim sugeriu estudar a divisão do trabalho a partir da ótica da solidariedade e da coesão social, ou seja, como produto da conduta moral dos indivíduos. Um de seus principais interesses analíticos na formação da solidariedade foi o direito, que diferentemente de alienação, ele considerou como expressões dos códigos morais e principal fator de ordenamento social, o que o aproxima de Hobbes e o distancia de Rousseau. De forma também diferente de Marx, que viu a religião como fator de alienação, Durkheim considera que a religião é uma manifestação do caráter moral das sociedades e, por essa via, ele inferiu a articulação entre as dimensões da religião e do conhecimento como sistemas de categorização da dimensão simbólica da vida social. 
Quando Durkheim fala sobre sociedade política (DURKHEIM, 1983b), remetese a uma organização que constitui um poder cuja ação os indivíduos estão sujeitos, e não há sociedade política sem a convivência de uma pluralidade de indivíduos, famílias e grupos diferentes. Sendo assim, a sociedade política é um grupo complexo do qual o Estado é órgão eminente, e não apenas um instrumento de canalização de interesses, pois é por meio dele que se torna possível dar organicidade aos grupos e subgrupos. Mas, para Durkheim (1983b), quais fins persegue o Estado? Ele traz uma resposta individualista para essa questão, pois considera que o Estado deve prevenir os maus efeitos das associações e promover o desenvolvimento dos indivíduos, ou seja, as funções do Estado devem perseguir fins superiores, que são sociais, de modo que ele trabalhe pela glória da sociedade.

É interessante fazer um contraste disso com tudo o que foi proposto pelos outros autores até agora, principalmente por Hobbes, Rousseau e Marx. Para Durkheim, o Estado, embora amplie suas funções, não pode descuidar dos indivíduos, pois os direitos dos indivíduos são obras do próprio Estado, nessa perspectiva, quanto mais forte é o Estado, mais o indivíduo é respeitado, pois é através do Estado que os indivíduos existem moralmente. Portanto, em Durkheim, a base dos direitos individuais não está fundamentada na noção de "natureza individual", mas sim no valor moral que a sociedade atribui ao indivíduo, e esse culto à pessoa humana faz com que o Estado se volte cada vez mais para a proteção dos indivíduos, pois ele é um órgão de disciplina moral e não desenvolve apenas funções econômicas e mercantis.

\subsection{Weber e a relação entre modernidade, racionalidade e visões de mundo}

Max Weber (1864-1920) foi praticamente contemporâneo de Durkheim, e igualmente é tido como um clássico da sociologia, sendo apontado o fundador da disciplina na Alemanha. Assim como Marx e Durkheim, Weber também tinha um projeto de sociologia da religião. No texto Rejeições religiosas do mundo e suas direções, Weber (1982) parte de uma história comparada e de uma psicologia social das religiões para compreender as diferenças entre dois tipos de religiões ao conferir sentido ao mundo, e emprega o misticismo e o ascetismo como conceitos polares, sendo o primeiro tipo predominantemente do mundo oriental e o segundo do ocidental. 
Essa polaridade, consoante Weber, pode ser compreendida em matéria da rejeição religiosa do mundo, uma vez que a ascese ativa é o fim da ação almejada, como um instrumento divino, por meio de Deus, enquanto a posse contemplativa da salvação da mística pretende constituir um ter e não um agir. Basicamente, ele considera que, para a ascese, o indivíduo é um instrumento do divino, conquanto a mística considera-o um receptáculo, e a oposição se dá quando os ascéticos exercem a ação dentro do mundo, ou seja, a ascese intramundana decorre do trabalho e da profissão, enquanto a mística renuncia radicalmente ao mundo, isto é, possui uma contemplação de fuga do mundo. Por essa via, Weber compreende a relação entre religião e ética econômica, nas quais os impulsos práticos das ações religiosas configuram móbeis para certas ações, de modo que esses sistemas simbólicos não determinam as formas de ação, mas se relacionam, pois significados culturais estão intimamente relacionados com a ação instrumental.

Nessa perspectiva, Weber compreende que o modo como se constituem algumas práticas no mundo vem da conduta religiosa, pois essas religiões oferecem uma imagem e um sentido ao mundo, uma por meio da redenção, e a outra, da salvação. Sendo assim, os móbeis dos tipos de ação mística e ascética perpassam por interesses materiais e ideais, seja para sobreviver, seja para conseguir a salvação ou a redenção, mas ambas constituindo sistematizações racionais das condutas de vida, análogo ao uso da razão em Hobbes e na razão prática de Rousseau, e formas próprias de imputar sentido ao mundo. Portanto, a cultura não consiste na quantidade de bens culturais apreendidos pelos indivíduos, mas na seleção destes por eles e, principalmente, como os bens culturais se relacionam com suas tomadas de posições instrumentais quanto ao mundo e na conferência de sentido àquilo que pensam e fazem.

Weber ainda examina as tensões entre a racionalidade religiosa, regida e legitimada por seus sentimentos de ética fraternal, empatia e suas normas, e outras esferas sociais do mundo moderno que são regidas por outras racionalidades e sentimentos, como as esferas estética, erótica, intelectual, econômica e política, sobretudo quando esta última carrega a racionalidade formal institucionalizada e que, portanto, possui sua própria ordem e legalidade por meio do Estado. Para Weber, quanto mais racional se tornava a ordem política, tornavam-se mais agudos os problemas dessas tensões, pois o fim do Estado é salvaguardar a distribuição externa e interna de poder, e essa finalidade pode 
parecer insensata às religiões universalistas da salvação, salientando que pode ser diferente para as religiões da contemplação. Sendo assim, Weber entende que a indiferença mútua entre religião e política, principalmente quando ambas são completamente racionalizadas, é ainda mais intensa, pois a política pode entrar em concorrência direta com a ética religiosa.

“O Estado é uma associação que pretende o monopólio do uso legítimo da violência, e não pode ser definido de outra forma” (WEBER, 1982, p. 383). Nessa perspectiva, Weber sugere que somente esse recurso à violência é que constitui essa associação política, definindo o Estado moderno em termos de seus meios específicos e não de seus fins, e o meio específico peculiar ao Estado é o uso da força, e somete ele tem o direito de uso. Portanto, Weber (2009) entende que a racionalidade atua tanto na ação quanto na estrutura, uma vez que ele define a ação racional como aquela que procura meios eficientes para atingir fins, ou seja, a ação instrumental ou teleológica e, na esfera estrutural, quando ocorre a dominação racional legal, em que a autoridade é impessoal e é validada por meio de estatutos legais ou regras racionalmente criadas que visam validade impessoal para todos os indivíduos, sendo o Estado burocrático, mediante a condução da rotina cotidiana da máquina burocrática, o principal exemplo tomado pelo autor de legitimidade racional burocrática na sociedade moderna.

\section{Considerações finais}

Feita essa revisão bibliográfica, este artigo não almeja consolidar conclusões, e sim fazer algumas considerações e, a partir daí, projetar uma hipótese. O ponto de partida é Hobbes, que foi um dos primeiros autores a pensar sobre as características da natureza humana por meio da ideia de homem natural. Ao pensar sobre a base dos comportamentos dos homens, considerando suas sensações físicas e psicológicas, é possível que Hobbes tenha proposto o germe da noção de indivíduo, se a categoria homens for análoga à categoria indivíduos. Hobbes também insere as noções de liberdade e igualdade, estas que permeiam quase todo o debate exposto aqui em relações de continuidades e descontinuidades.

O estado de natureza pensado por Hobbes a partir da liberdade, paixão, egoísmo, desconfiança e violência, pode ser visto como uma representação de uma relação entre 
indivíduos e sociedade da guerra civil que ele vivenciou. Já o Estado político, ou Leviatã, é um modelo de sociedade em que ele propõe idealmente outra relação entre indivíduos e sociedade por meio do controle da natureza humana. O Leviatã, para Hobbes, é o Estado racional, e este é um meio artificial e eficiente capaz de reconhecer as características ruins dos homens naturais e controlá-las pela imposição de códigos e, consequentemente, criar moralidade. Nessa perspectiva, a relação entre homens no Estado político e no estado natural pode ser vista, hipoteticamente, como representações típicas ideais, ou como metáforas filosóficas, de relações entre indivíduos e sociedade.

Além disso, é interessante fazer uma leitura histórica da capa ${ }^{1}$ da edição original do livro de Hobbes, O leviatã — publicado em 1651 - cuja autoria é atribuída a Abraham Bosse, um artista francês que Hobbes conheceu em Paris. Ela resume a obra do autor. A coroa na cabeça do soberano define o sistema político que Hobbes concebe como melhor para criar moralidade, a monarquia, embora ele não deixe isso claro em seu texto. A espada na mão direita do rei representa o monopólio da violência para gerar segurança, pois não existe pacto sem espada; e abaixo da espada, o castelo, a coroa, o exército. $\mathrm{O}$ cetro, na mão esquerda, representa a concentração de poderes do monarca e, abaixo do cetro, a igreja e outras imagens que representam a legitimidade religiosa do Estado, pois ele é também eclesiástico. O mais interessante no desenho é o corpo do monarca, sua armadura é formada por vários homens, e este corpo social representa o contrato estabelecido pelos homens, uma vez que o Estado também é civil. E a proporção do corpo do monarca em relação ao tamanho das outras coisas, como o território, passa a sensação de autoridade e controle. É também interessante salientar essa leitura, porque muitos aspectos dela podem estar relacionados com ideias de outros autores.

Rousseau, 100 anos depois de Hobbes, estabelece com o pensamento dele uma série de debates em relações de continuidades e descontinuidades. Ele tenta implodir o alicerce das ideias de Hobbes para fundar o Estado por meio de algumas características dos homens supostas pelo próprio Hobbes, mas que não foram muito enfatizadas em $O$ leviatã. Rousseau recupera a ideia da benevolência dos homens por meio das categorias piedade e empatia, como elementos da bondade natural, sendo as bases da relação entre

\footnotetext{
${ }^{1}$ Esta capa pode ser facilmente visualizada por meio de uma simples busca pelo Google.
} 
indivíduo e sociedade no seu suposto estado de natureza. Sobre o Estado político, Rousseau também se aproxima de Hobbes ao concordar que tal Estado aliena os direitos naturais por meio da razão, e se distancia dele ao conceber a ideia de Estado político como contrato que deve preservar a liberdade e a igualdade, como fruto da vontade geral dos homens, esta que pode ser análoga à do corpo social da capa do Leviatã, ou seja, é a vontade geral que tem o poder, não o monarca. Por essa via, Rousseau pensa em um modelo sociopolítico inspirado na democracia ateniense, e as relações entre indivíduos e sociedade inerentes a este modelo são baseadas nas ideias de liberdade, igualdade e piedade.

Hume foi praticamente contemporâneo de Rousseau. Ele rompe com as ideias de homem natural e estado de natureza. Pare ele, nem a razão ou o interesse público são capazes de prover um ordenamento sociopolítico justo, que só se tornaria possível via uma convenção, também do corpo social, que estabelecesse limites e diferenças entre os interesses público e privado. Por esse caminho filosófico, Hume propõe que os homens aprenderam que viver em sociedade é vantajoso, e esta é um recurso natural, de modo que vêm da natureza humana o interesse e a necessidade da união em sociedade, da mesma forma a sociedade é um recurso da natureza humana. Por esse prisma de continuidades e descontinuidades, Hume estabelece que a relação entre indivíduo e sociedade simplesmente é natural, e que as supostas características naturais da conduta humana, como o egoísmo e empatia, estarão sempre presentes na sociedade.

Anos depois de Hume, Tocqueville também se distancia das especulações sobre o homem natural e natureza humana, mas em suas análises sobre a democracia, comparando os EUA, Inglaterra e França, ele recorre às ideias de liberdade e igualdade como categorias analíticas. Interessante notar como Tocqueville parte de realidades sociais observadas e comparadas, algo que pode ser análogo ao contemporâneo trabalho de campo, para uma filosofia sobre a democracia. Ela, para Tocqueville, seria a soberania do povo expressa na vontade geral, de modo que igualdade e liberdade fossem ponderadas para estabelecer organicidade sociopolítica e, é desta maneira que ele pode ter pensado a relação entre indivíduo e sociedade em sua obra.

Marx é praticamente contemporâneo de Tocqueville e, por meio de sua análise social, entende que a relação entre o Estado, os direitos, os ideais de liberdade e igualdade 
servem apenas aos interesses da classe burguesa em detrimento da classe proletária. Inserindo a noção de classes sociais como subdivisões do corpo social, e recuperando a natureza racional e conflitiva dos homens, Marx concebe o Estado e os supostos direitos, assim como os indivíduos e a sociedade, como categorias submetidas à historicidade, e se insere no debate das continuidades e descontinuidades da antropologia filosófica nas ciências sociais, assim como no debate das relações entre indivíduo e sociedade. A partir daí Marx pensa um modelo sociopolítico baseado nas observações dessas relações, e neste modelo, a classe proletária ia racionalmente tomar consciência do antagonismo com a classe burguesa, se organizar, assumir o Estado e, por meio deste, acabar com a propriedade privada, a divisão do trabalho, a alienação, a divisão da sociedade em classes, o capitalismo e, por fim, com o próprio Estado.

Durkheim é outro autor que traz uma representação social a partir do entendimento de realidades observadas inerentes aos fatos sociais, e das relações entre indivíduo e sociedade. Diferentemente de Marx, Durkheim entende que a divisão social do trabalho não causa conflito e sedição, mas solidariedade, ou seja, ela é um elemento básico para a coesão do corpo social. Em relação às leis e direitos, como fatores de ordenamento social e causadores de solidariedade, Durkheim parece imbricar noções de Hobbes e Rousseau, assim como sobre o Estado e sua função para com os indivíduos.

Weber é contemporâneo de Durkheim e, assim como este, recupera o caráter positivo da religião em sua análise, propondo que ação racional, prática intrínseca a esta esfera do corpo social, possui uma forma peculiar de atribuir sentido ao mundo. Recuperando também a natureza conflitiva dos homens, Weber analisa a tensão da racionalidade religiosa com outras esferas do corpo social, sendo uma delas a política, sobretudo quando se trata da política formal institucionalizada pelo Estado por meio da ação racional sistemática. Nesse aspecto, pode-se supor que Weber entra em debate e relações de continuidades e descontinuidades com as ideias de razão prática e razão sistemática de Rousseau. Além disso, Weber recupera a noção hobbesiana de que o Estado possui o monopólio legítimo da violência como meio específico para promover a ordem tanto interna quanto externa, e que somente esse recurso à violência é que constitui o Estado como associação política. Por esse caminho, Weber então representa a relação 
entre indivíduo e sociedade, e considera que a racionalidade atua tanto na ação quanto na estrutura.

Sem mais delongas considerativas, primeiramente é interessante salientar o lapso temporal entre esses autores, sendo que poucos deles foram contemporâneos, e que cada um representa à sua maneira a relação entre indivíduo e sociedade de seu contexto, seja essa representação por meio de metáforas e dialéticas filosóficas, de observações das sociedades, de leituras históricas, comparações, dentre outros enfoques analíticos. Ademais, pode-se presumir que existe um escopo codificado que permeia todas as análises desses autores, sendo que tal escopo carrega um debate repleto de continuidades e descontinuidades imanentes a essas categorias analíticas codificadas por esses autores, em que cada autor se aproxima de uns e se distancia de outros e, concomitantemente, traz sua contribuição original.

Portanto se pode depreender a hipótese de que as noções de indivíduo e sociedade, na sociologia clássica de Marx, Durkheim e Weber, podem ter sido forjadas a partir deste debate, que pode ter tido como ponto de partida a antropologia filosófica de Hobbes, perpassando por Rousseau, assim como pelas intermediações de Hume e a análise socialfilosófica de Tocqueville. Nessa perspectiva, é possível que Hobbes, Rousseau, Hume e Tocqueville já trouxessem, implicitamente em suas análises, as relações entre homens, sociedade e Estado político, podendo tais relações serem análogas a algumas das relações entre indivíduo e sociedade nas sociologias clássicas de Marx, Weber e Durkheim. Porém, desde Hobbes, cada um desses autores traz uma representação de tal relação e com sua contribuição original, seja a partir do debate inerente a um corpo analítico codificado, em que cada um realça suas continuidades e descontinuidades com outros, assim como de seus contextos de vivências e análises, uma vez que cada um compreendeu e interpretou, à sua maneira, a relação entre homens, analogamente a indivíduos e organização sociopolítica.

\section{Referências}

DURKHEIM, Émile. Da divisão do trabalho social; As regras do método sociológico; O suicídio; As formas elementares da vida Religiosa. 2. ed. São Paulo: Abril Cultural, 1983a. (Coleção os pensadores). 
DURKHEIM, Émile. Lições de sociologia: a moral, o direito e o estado. São Paulo: Edusp, 1983b.

DURKHEIM, Émile. Coleção sociologia. São Paulo: Ática, 2000.

GIDDENS, Anthony. Capitalismo e moderna teoria social. Lisboa: Presença, 1984.

HOBBES, Thomas. O Leviatã. São Paulo: Abril Cultural, 1974. (Coleção os pensadores).

HUME, David. A treatise of human nature. Oxford: University Press, 2007.

MARX, Karl. Sobre a questão judaica. São Paulo: Boitempo, 2010.

MARX, Karl.; ENGELS, Friedrich. A ideologia alemã. Rio de Janeiro: Civilização Brasileira, 2007.

ROUSSEAU, Jean-Jacques. Discurso sobre a origem e os fundamentos da desigualdade entre os homens. São Paulo: Martin Claret, 2010.

ROUSSEAU, Jean-Jacques. Do contrato social. São Paulo: Martin Claret, 2012.

ROUSSEAU, Jean-Jacques. Emílio, ou da educação. São Paulo: Martins Fontes, 2014.

TOCQUEVILLE, Alexis de. A democracia na América: sentimentos e opiniões de uma profusão de sentimentos e opiniões que o estado social democrático fez nascer entre os americanos. São Paulo: Martins Fontes, 2000. (Livro 2).

TOCQUEVILLE, Alexis de. A democracia na América: leis e costumes de certas leis e certos costumes políticos que foram naturalmente sugeridos aos americanos por seu estado social democrático. 2. ed. São Paulo: Martins Fontes, 2005. (Livro 1).

WEBER, Max. Rejeições religiosas do mundo e suas direções. In: Ensaios de sociologia. Rio de Janeiro: LTC, 1982, p. 371-410.

WEBER, Max. Economia e sociedade: fundamentos da sociologia compreensiva. Brasília: UnB, 2009. (Volume 1).

Recebido em: 20/04/20.

Aceito em: 16/05/20. 